\title{
EFFECTS OF INFANTILE GUSTATORY STIMULATION ON LATER AVERSION TO QUININE HYDROCHLORIDE IN THE RAT
}

\author{
SHUZO OHI ${ }^{1}$ \\ Tokyo Medical and Dental University ${ }^{2}$
}

\begin{abstract}
Effects of an early experience with a gustatory stimulus on later sensitivity to that stimulus was studied in 36 rats. A quinine hydrochloride (Q-HCl) solution $\left(10^{-3} \mathrm{M}\right)$ or deionized water (D.W.) was directly applied to the tongue every day for 20 days starting from the age of two days postnatally. In a 2-bottle choice between $\mathrm{Q}-\mathrm{HCl}$ and D.W. at the age of 39 days, the Q-HCl stimulated rats avoided a lower concentration of $\mathrm{Q}-\mathrm{HCl}$ than that avoided by the D.W. stimulated rats. Rats similarly stimulated with $\mathrm{Q}-\mathrm{HCl}$ for 20 days, but started from the age of 31 days, and tested at 67 days postnatally, did not reject the concentration of $\mathrm{Q}-\mathrm{HCl}$ avoided by the rats stimulated before weaning. The results suggest that a gustatory stimulus frequently given in a preweaning period enhances the sensitivity to that stimulus at a later time, but that the same stimulus given after weaning fails to produce such an effect.
\end{abstract}

The habits of adult taste preferences in man are experientially and generally thought to be acquired through early taste experiences in infancy and childhood. But how early experience leads to the formation of taste preferences or aversions has not been clarified. Galef and Henderson (1972) reported that weanling rats preferentially selected the same food which their mother had eaten during lactation, presumably on the basis of taste stimulation from the mother's milk. Capretta and Rawls (1974) also showed that, when pups tasted garlic via the mother's milk and in solution during weaning, they greatly preferred that taste, relative to con-

I I thank Professor Masamichi Ichioka and Dr. Toshihide Sato for their encouragement during the work and Mrs. Kumiko Sugimoto for her valuable help in preparing the manuscript. I also thank Ms. M. Lynne Roecklein, Gifu University, for her critical reading of the manuscript.

Requests for reprints should be sent to Shuzo Ohi, Department of Psychology, Faculty of General Education, Gifu University, Nagara, Gifu, 502 Japan.

${ }^{2}$ Presently at Gifu University. trol animals, not only in a test immediately after their experience but also in a retest about 50 days later. Both the above reports claimed that the early experience of a flavor increased the pups' acceptance of the flavor. However, it may be that those pups were also given stimuli other than taste via the mother's milk, such as olfactory, tactile, trophic, and so on. Moreover, pups given milk from one mother cannot be divided into subgroups, so the rearing effects of the mother cannot be controlled. To clarify the effect of infantile stimulation of taste on later behavior, it would be desirable to restrict the variables as much as possible to taste manipulations.

Warren and Pfaffmann (1958) stimulated guinea pig pups directly with sucrose octaacetate, a bitter substance. As the guinea pig is a precocial species, the pups were stimulated by means of drinking the stimulus solution in place of the usual water. The pups, given this treatment for two or three weeks after birth, did not avoid the bitter taste solution in a test immediately after stimulation, but this 
phenomenon did not occur in a retest at three or four months of age. These results, especially the former, might have been produced because of an adaptation to the bitter taste. Moreover, the guinca pig might not be a suitable experimental subject for bitterness testing, for the guinea pig did not avoid a $10^{-3} \mathrm{M}$ (molar-concentration) quinine-hydrochloride solution (typical bitter substance: Q-HCil) (Warren \& Pfaffmann, 1958), which is about 100 times higher than the human's threshold concentration of bitterness (Pfaffmann, 1959).

In the present experiment, rats were used as subjects, for the threshold concentration at which rats avert $\mathrm{Q}-\mathrm{HCl}$ solution is about $10^{-5} \mathrm{M}$ (Pfaffmann, 1960), the same as man's, so that the rat is thought to be a suitable subject for a test of sensitivity to bitterness. Unfortunately, the method of Warren and Pfaffmann (1958) cannot be used with infant rats because of their altricial state. Instead, the pups' tongues were stimulated directly with filter paper moistened with stimulus solution in order to ascertain the effects of infantile stimulation on later behavior toward Q$\mathrm{HCl}$.

\section{EXPERIMENT I}

Experiment I was designed to determine whether and how infantile stimulation during the preweaning period could influence taste behavior in the postweaning period.

\section{Method}

The subjects were pups of eight litters of Wistar albino rat accompanied by their mothers, from seven to 13 pups per litter. The day of birth was counted as Day 1. They were maintained with the ${ }^{(R)}$ CII diet (Clea Japan, INC) for rats and in a temperature-controlled room at $20^{\circ} \mathrm{C}$.

Apparatus. The choice-testing apparatus was a plastic detention cage with six compartments, each $25 \mathrm{~cm}$ long, $15 \mathrm{~cm}$ wide, and $20 \mathrm{~cm}$ high, with metal grid floors. The walls between compartments and the two end walls were gray plastic plates, and the front and back panels and ceiling (or lid) were transparent acrylic plates. There were two rectangular holes $(5.0$ $\mathrm{cm}$ long and $1.5 \mathrm{~cm}$ wide), side by side in the front panel of each compartment, through which two $50 \mathrm{ml}$ graduated drinking tubes were inserted.

Procedure. New-born pups with their mothers were taken for this experiment at two days post-partum and maintained until the termination of stimulation in an aluminum cage (23 $\mathrm{cm}$ long, $33 \mathrm{~cm}$ wide, and $13 \mathrm{~cm}$ high) on which was put a lid of wire netting and whose floor was covered with sawdust. Each day half of the pups of each litter were stimulated with a $10^{-3} \mathrm{M}$ Q-HCl solution (Q-HCl group) and the other half were stimulated with deionized water (D.W.: D.W. group). During the stimulation period, the mother of a litter was removed from her cage and each pup was picked up in turn and stimulated by inserting a strip of filter paper $(2 \mathrm{~mm} \times 15 \mathrm{~mm})$ moistened with Q-HCl solution or D.W. into its mouth, and weighed afterward every other day. Immediately after the above treatment for all pups in one litter, their mother was returned to the home cage. The duration of separation between pups and mother was about $30 \mathrm{sec}$ per one pup without weighing or about $50 \mathrm{sec}$ with weighing, times the size of the litter, which ranged from seven to 13 pups per litter. The pups were handled once per day between 9:30 a.m. and 10:30 a.m. from two to 21 days old.

At 22 days of age, the pups were weaned, separated into same-sex groups, and raised without any further treatment for ten days thereafter. Ten days later, on Day 32, one male pup of each group from each litter was given a two-bottle taste preference test with a Q-HCl solution and D.W. Tests were conducted with the subjects in individual detention cages in a temperature-controlled room $\left(19\right.$ to $22^{\circ} \mathrm{C}$ ). Each subject had continuous access both to food and to the two solutions available from two tubes. Except for an initial adaptation period of seven days from Day 32, during which only D.W. was available, subjects were 
offered a choice between D.W. and different concentrations of Q-HCl dissolved in D.W. Four concentrations of Q-HCl solution were used and presented in the following order: $5.6 \times 10^{-6} \mathrm{M}$ (4 days), $10^{-5} \mathrm{M}(4), 1.8 \times 10^{-5}$ M (4), and $3.2 \times 10^{-5} \mathrm{M}(2)^{3}$. The bottle position of the taste solution was changed daily to the right (R), left $(L), L$, and $R$, or $L, R$, $R$, and $L$. Consumption of each solution was measured for $23 \mathrm{hrs}$. In the residual time of $1 \mathrm{hr}$, the rats were weighed, cages were cleaned, and tubes were refilled and reset. The choice rate for the Q- $\mathrm{HCl}$ solution at a given concentration stage was calculated from the intake volume of each solution as follows:

Choice rate

$$
\begin{aligned}
& =\frac{\text { Combined intake of } \mathrm{Q}-\mathrm{HCl}}{\text { Combined intake of } \mathrm{Q}-\mathrm{HCl}} \\
& \text { +Combined intake of D.W. }
\end{aligned}
$$

\section{Results and Discussion}

The pups in both groups developed normally during the entire time of this experiment. By the time of weaning at 22 days, the mean weight of the pups had increased to $36.8 \pm 5.3 \mathrm{~g}( \pm S D)$ in the Q-HCl group and $37.0 \pm 4.4 \mathrm{~g}$ in the D.W. group. Body-weight increase continued well till the tests finished, and no difference between the groups was significant at any stage of development. A premature death prior to weaning occurred in six of eight litters, but dead pups were fewer in the Q-HCl group than in the D.W. group, two and five deaths respectively. From the above, it appears that the stimulating procedure used in this experiment did not disturb the normal development of pups either in preweaning or choice-test periods.

${ }^{3}$ The choice test at a concentration stage of $3.2 \times 10^{-5} \mathrm{M}$ Q-HCl was conducted for only two days because of the limitation in our facilities. We have two apparatus, which limited the experiment to six pairs at the most simultaneously. So this experiment was conducted repeatedly by dividing the subjects into two series. But the pups of the second series reached the age for testing before the first series had finished.
Figure I summarizes the results obtained in the ascending concentration series for the Q-HCl and D.W. groups in this experiment. The lower sets of points show that in both groups, the higher concentrations of Q-HCl solutions were avoided, $F(3,42)=18.63, p<.01$, the lower Q-HCl concentrations less so. The $\mathrm{Q}-\mathrm{HCl}$ group, however, avoided the stimulus solution used in this experiment more than the D.W. group, $F(1,14)=7.27, p<.05$. This statistical difference seems to be due to the marked differences in aversion at the initial stages in the ascending concentration series of the stimulus solution. A concentration of $5.6 \times 10^{-6} \mathrm{M}$ Q-HCl solution was avoided by the Q-HCl group, in which the choice rate for all subjects was less than $50 \%$, while it was not avoided by the D.W. group. The difference between groups approached significance, $t(7)=2.177, .05<p<.10$; by the CochlanCox method. At the concentration stage of $10^{-5} \mathrm{M}$, the difference between groups was significant, $t(14)=2.599, p<.05$, that is, the Q-HCl group further avoided the stimulus solution, but the D.W. group did

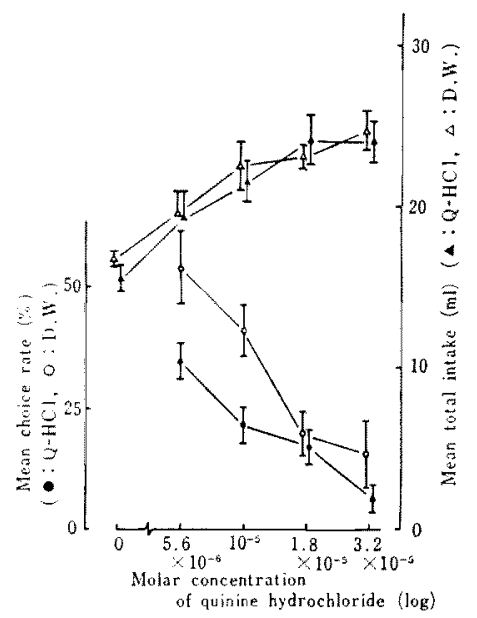

Fig. 1. Mean choice rate and mean total intake (and the standard error for cach mcan) as a function of molar concentration of quinine hydrochloride ( $\log$ ) in Experiment $I$. The number of subjects was eight in each group. 
not always reject it. Both the Q-HCil and D.W. groups almost completely avoided higher concentrations and the two groups were not significantly different. Total intakes at each stage showed no difference between groups throughout this experiment, although, as the subjects grew older, the volume of total intake increased, as shown in the upper portion of Fig. 1.

These results suggest that infantile stimulation makes the rat more sensitive to Q-HCl ; Q-HCl-stimulated rats avoided a bitter taste at lower concentrations than their non-stimulated siblings. This avoidance effect of infantile bitter-taste stimulation on taste behavior was observed at the lower concentrations used in this experiment, whereas a concentration of $10^{-5}$ $M$ or so of Q-HCl solution seems to be the common threshold for the rat to avoid it (Pfaffmann, 1960).

\section{EXPERIMENT II}

Experiment II was designed to examine how taste stimulation at the postweaning period acted on later taste behavior.

\section{Method}

Subjects. The subjects were 20 postweaning male rats of Wistar albino strain obtained from a local dealer at 22 days old, not accompanied by their mothers. They werc maintained with $a^{(R)} \mathrm{CII}$ diet and kept in the same temperaturecontrolled room as in Experiment I.

Apparatus. The same choice-testing apparatus used in Experiment $\mathrm{I}$ was used in this study.

Procedure. The procedure for the present experiment was almost identical to that of Experiment $I$ except that subjects were 31 days old at the beginning of the experiment. Rats were kept without any treatment until 31 days of age. At 31 days old the subjects were divided randomly into a $\mathrm{Q}-\mathrm{HCl}$ group and a D.W. group and were stimulated with each fluid in the same manner as in Experiment I for 20 days thereafter (Day 31-50). The filter paper was $4 \mathrm{~mm} \times 20 \mathrm{~mm}$. The pups were simply maintained for ten days. Then, after an initial adaptation period of seven days beginning at 61 days old, two-bottle taste tests of four concentrations of Q-HCl were administered, as in Experiment I, except that the highest concentration stage also took four days. The bottle position, the procedure measuring intake and body weight, and the calculation of choice rate were the same as those of Experiment I.

\section{Results and Discussion}

Figure 2 summarizes the results obtained in the ascending concentration series for the Q-HCl and D.W. groups in this experiment. In both groups, the higher concentrations of $\mathrm{Q}-\mathrm{HCl}$ solution were most avoided, $F(3,54)=18.52, p<.01$, as in Experiment I. However, neither the Q-HCil group nor the D.W. group avoided the $5.6 \times 10^{-6} \mathrm{M}$ or $10^{-5} \mathrm{M}$ Q-HCl solution. In the subsequent concentration tests, both groups developed a tendency to avoid Q-HCl solution at $1.8 \times 10^{-5} \mathrm{M}$ and completely avoided $3.2 \times 10^{-5} \mathrm{M} \mathrm{Q}$ $\mathrm{HCl}$ solution. These phenomena were almost comparable to those appearing in

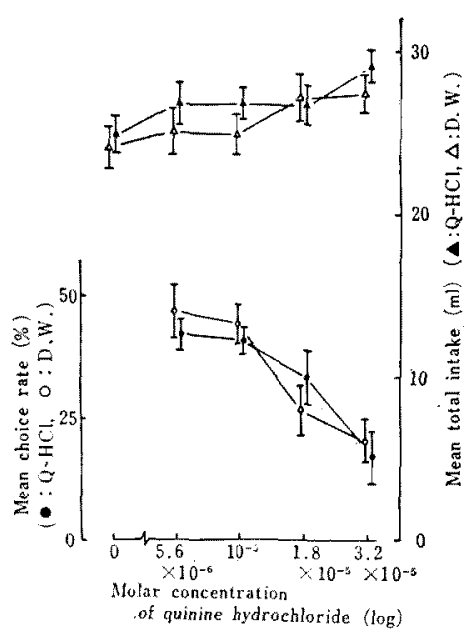

Frg. 2. Mean choice rate and mean total intake (and the standard error for each mean) as a function of molar concentration of quinine hydrochloride $(\log )$ in Experiment II. The number of subjects was ten in each group. 
the D.W. group in Experiment I, suggesting that the Q-HCl group in this experiment was not influenced by early stimulation with $10^{-3} \mathrm{M}$ Q-HCl solution, or in other words, that the postweaning period, when subjects were stimulated with $10^{-3}$ $\mathrm{M}$ Q-HCl solution, was too late to influence the taste habit.

\section{General Discussion}

The results reported here suggest that early experience of infantile stimulation with $\mathrm{Q}-\mathrm{HCl}$ during the preweaning period enhances sensitivity to that taste, at least as it is expressed by their avoidance of that taste in a two-bottle test. But 20 days of taste stimulation after weaning had no appreciable effect on taste avoidance.

The facts appearing in this report differ from prior reports (Galef \& Henderson, 1972 ; Capretta \& Rawls, 1974) showing that infantile stimulation by a given flavor enhanced the subject's acceptance of the flavor. Disagreement between these results may be due to the difference between stimuli used in each experiment and may be explainable if two mechanisms by which infantile stimulation affects later taste behavior are supposed, namely, acceptance of and sensitivity to a given flavor. The Q-HCl solution used in this report is universally rejected by animals in stereotypic behavior of aversion (Garcia \& Hankins, 1975). Since rejection of a bitter taste by an organism is a powerful, innate mechanism (Garcia \& Hankins, 1975), the disposition to reject Q-HCl may be retained in spite of infantile stimulation. In addition, infantile stimulation may even enhance sensitivity to $\mathrm{Q}-\mathrm{HCl}$, so that the stereotypic behavior of aversion emerges at lower concentrations than it would without such stimulation. On the other hand, the stimuli used in prior experiments were foods with differing flavors (Galef \& Henderson, 1972) or a garlic solution (Capretta \& Rawls, 1974), which are rather neutral in the aversion-preference dimension in naive animals and do not trigger the stereotypic behavior, though there may be neophobia. Therefore, as subjects become more familiar with a neutral substance, they are more apt to accept the substance, and, probably, the sensitivity to the substance is likely to be enhanced.

The present results also differ from those reported by Warren and Pfaffmann (1958). Guinea pigs stimulated directly with sucrose octaacetate during infancy did not reject the stimulating solution immediately after the stimulation period in a two-bottle taste test, but did reject it in a retest at three or four months. However, only the $10^{-3} \mathrm{M}$ concentration for a test and retest might be too high to examine the effect of infantile stimulation, since all subjects completely rejected that concentration in the test immediately after the stimulation period, except for those stimulated beforehand. That these latter subjects did not necessarily reject it might have been due to their adaptation to the solution during the stimulating period, when they drank only the saturated aqueous solution of sucrose octaacetate. Thus the difference between their results and those presented in this paper may be caused by the difference in testing methods. To examine the effect of infantile stimulation on sensitivity precisely, one might have to use various concentration stages of a stimulating substance as one of the solutions when using the two-bottle taste-test method, as was done in the present experiment.

From the above, it might be suggested that infantile stimulation by a taste substance affects two mechanisms of the ingestive system, by enhancing sensitivity and modifying aversion-preference behavior. The former may be thought to be a general effect but the latter might be differently affected according to the characters of the substances experienced. 


\section{REFERENCES}

Capretta, P.J., \& Rawl.s, L. H., III. 1974 Establishment of a flavor preference in rats: Importance of nursing and weaning experience. Journal of Comparative and Physiological Psychology, 86, 670-673.

Galer, B. G., Jr., \& Henderson, P. W. 1972 Mother's milk: A determinant of the fecding preferences of weaning rat pups. Journal of Comparative and Physiological Psychology, 78, 213219.

Gargia, J., \& Hankins, W. G. 1975 The evolu- tion of bitter and the acquisition of toxiphobia. In D. A. Denton, \& J. P. Coghlan (Eds.), Olfaction and laste, Vol. V. New York: Academic Press. Pp. 39-45.

Praffmann, C. 1959 The sense of taste. In H. W. Magoun (Ed.), Handbook of physiology, Sect. I, Vol. 1. Washington, D. C.: American Physiological Society. Pp. 507-534.

Praprmann, C. 1960 The pleasures of sensation. Psychological Review, 67, 253-268.

Warren, R.P., \& Praffmann, C. 1958 Early experience and taste aversion. Journal of Comparative and Physiological Psychology, 52, 263-266. (Received Dec. 6, 1978) 